\title{
Case Report \\ Pancreatic Perivascular Epithelioid Cell Tumour Presenting with Upper Gastrointestinal Bleeding
}

\author{
Christos Petrides, ${ }^{1}$ Kyriakos Neofytou, ${ }^{2}$ and Aamir Z. Khan ${ }^{2}$ \\ ${ }^{1}$ Department of Surgery, Nicosia Government Hospital, Palaios Dromos Lefkosias-Lemesou, No. 215, Strovolos, 2029 Nicosia, Cyprus \\ ${ }^{2}$ Department of Academic Surgery, Royal Marsden Hospital, Upper GI/HPB Unit, Fulham Road, London SW3 6JJ, UK \\ Correspondence should be addressed to Kyriakos Neofytou; kneophy2@gmail.com
}

Received 13 October 2014; Accepted 29 December 2014

Academic Editor: Francesco A. Mauri

Copyright ( $) 2015$ Christos Petrides et al. This is an open access article distributed under the Creative Commons Attribution License, which permits unrestricted use, distribution, and reproduction in any medium, provided the original work is properly cited.

\begin{abstract}
PEComa is a family of rare mesenchymal tumours which can occur in any part of the human body. Primary PEComas of the pancreas are extremely rare tumours with uncertain malignant potential. A 17-year-old female was admitted to the hospital due to melena. She required several transfusions. CT scan demonstrated a mass at the head of the pancreas measuring $4.2 \mathrm{~cm}$ in maximum diameter. An endoscopic ultrasound showed an ulcerating malignant looking mass infiltrating $50 \%$ of the wall of the second part of the duodenum in the region of the ampulla. Multiple biopsies taken showed extensive ulceration with granulation tissue formation and underlying large macrophages without being able to establish a definite diagnosis. We proceeded with pyloruspreserving pancreaticoduodenectomy. The postoperative course of the patient was unremarkable, and she was discharged on the 8th postoperative day. Histology examination of the specimen showed a PEComa of pancreas. Eighteen months after resection the patient is disease free. To the best of our knowledge this is the first time we describe a case of a pancreatic PEComa presenting with massive gastrointestinal bleeding.
\end{abstract}

\section{Introduction}

PEComa (perivascular epithelioid cell tumour) is a family of mesenchymal tumours consisting of perivascular epithelioid cells (PECs). PEComas are rare tumours that can occur in any part of the human body [1]. The most common tumors in the PEComa family are renal angiomyolipoma and pulmonary lymphangioleiomyomatosis, both of which are more common in patients with tuberous sclerosis complex [1-3]. Establishing the malignant potential of PEComas remains challenging although criteria have been suggested [1-3].

Primary PEComas of the pancreas are extremely rare tumors with uncertain malignant potential. Only twelve cases, including the one we report here, are published in the literature $[2,4-13]$. Surgical resection represents the only curative approach for this kind of tumours [1, 2, 4-13].

Here, we present a rare case of a patient with upper gastrointestinal bleeding due to an ulcerating head of pancreas PEComa. This patient underwent PPPD and 18 months after operation is disease free. To the best of our knowledge this is the first report of PEComa of pancreas manifesting with upper gastrointestinal bleeding.

\section{Case Report}

A 17-year-old female patient was referred to RMH due to melena caused by a mass at the head of pancreas. She presented at the local hospital 2 months before with melena. At that time she required several transfusions due to anemia (hemoglobin $6 \mathrm{~g} / \mathrm{dL}$ at presentation) and she underwent oesophagogastroduodenoscopy (OGD), colonoscopy, and Meckel's scan; all of them reported as normal. A CT scan revealed a mass at the head of pancreas (Figure 1).

At the time of referral she was asymptomatic. Her past medical history and the clinical examination were unremarkable. The review of the CT scan, which took place at the local hospital, demonstrated a lesion mass at the head of the pancreas measuring $4.2 \mathrm{~cm}$ in maximum axial diameter and $4.9 \mathrm{~cm}$ in the craniocaudal direction. This mass showed avid arterial phase enhancement with rapid washout, 

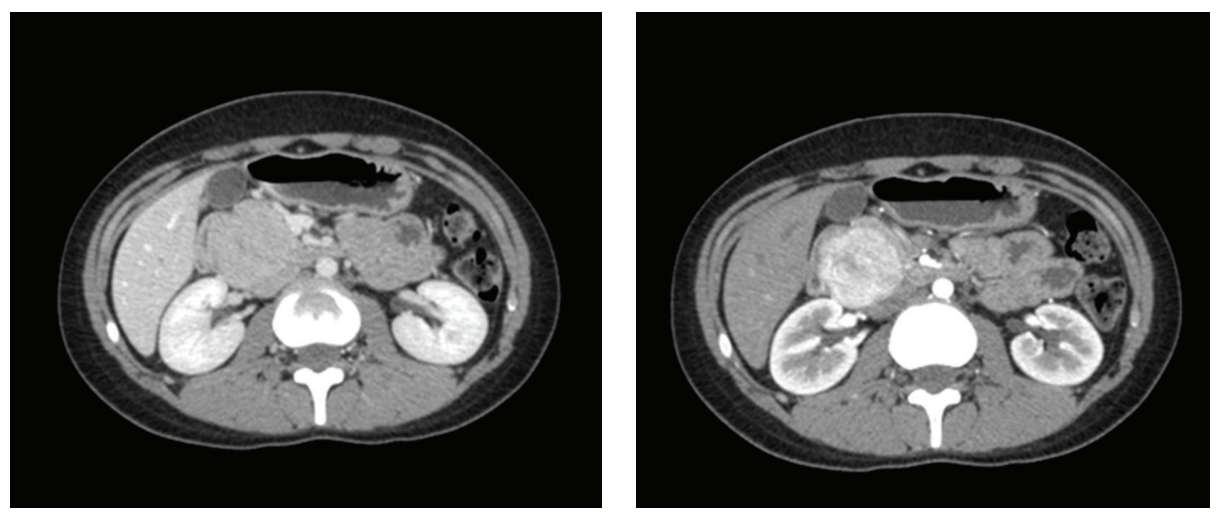

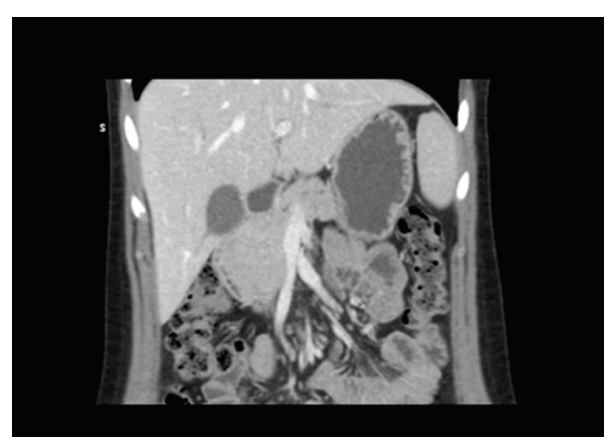

(a)

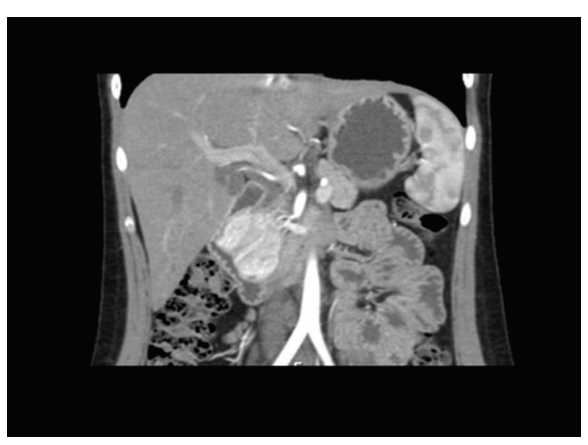

(b)

Figure 1: Abdomen computed tomography showing a mass at the head of pancreas. (a) Portal vein phase: isodense appearance of the mass to the rest of the pancreas. (b) Arterial phase: enhancement of the mass.

while it appeared almost isodense compared to the rest of the pancreas in the portal venous phase. Both pancreatic duct and common bile duct were prominent, with their diameter to upper normal limit. The SMV was abutment but not involvement. Extrapancreatic disease was excluded. These features were consistent with neoplasmatic mass of the head of pancreas, with the most possible pathology being a neuroendocrine tumour. The subsequent gut hormone test was normal (VIP, PP, gastrin, glucagon, somatostatin, chromogranin $\mathrm{A}$, and chromogranin $\mathrm{B}$ ).

An endoscopic ultrasound (EUS) was performed showing an ulcerating malignant looking mass infiltrating $50 \%$ of the wall of the second part of the duodenum in the region of the ampulla. Multiple biopsies taken showed extensive ulceration with granulation tissue formation and underlying large macrophages without being able to establish a definite diagnosis.

We proceeded with pylorus-preserving pancreaticoduodenectomy. The postoperative course of the patient was unremarkable, and she was discharged on the 8th postoperative day.

Histology examination of the specimen showed an ulcerated tumour that had an expansible margin surrounded by a fibrous pseudocapsule. The tumor was well vascularised and composed of large mainly epithelioid cells with clear granular or feathery cytoplasm. Some cells with more spindle appearance were seen. The nuclei were eccentric, and there were many vascular spaces within the tumor which were dilated and some had irregular outlines. Mitosis was infrequent and there was no necrosis. No vascular invasion was seen. The cells were positive stained for HMB45, Melan A and smooth muscle actin. They were negative for cytokeratin, chromogranin, CD56, S100, desmin, and calponin. The above features were consistent with a perivascular epithelioid cell neoplasm (PEComa). Peripancreatic lymph nodes were negative for tumor and the resection was complete. Eighteen months after resection the patient is disease free.

\section{Discussion}

The perivascular epithelioid cell was first described in 1943 by Apitz as an "abnormal myoblast" in renal angiomyolipoma [14]. Since the first report of a perivascular epithelioid "sugar" tumor in the pancreas from Zamboni et al. in 1996, a number of similar lesions have been described in virtually every anatomic site of the human body [2, 3, 15-19]. These tumors can arise in patients of any age, with gender difference due to female predominance $(7: 1)$ [3].

PEComas are well-circumscribed and set apart from the surrounding parenchyma by a thin capsule [20]. Histopathological examination of PEComas reveals nests and sheets of usually epithelioid but occasionally spindled cells with clear to granular eosinophilic cytoplasm, often found in close association with the blood vessel walls. The tumors demonstrate immunoreactivity for both melanocytic (HMB45 , melan-A, and microphthalmia transcription factor) and 
TABle 1: Reported cases of pancreas PEComas and symptoms at diagnosis.

\begin{tabular}{|c|c|c|c|c|c|c|}
\hline & Case & Sex & Age & Position & Size $(\mathrm{mm})$ & Symptoms \\
\hline 1 & Zamboni et al. (1996) [2] & $\mathrm{F}$ & 60 & Body & 20 & Abdominal pain \\
\hline 2 & Heywood et al. (2004) [4] & $\mathrm{F}$ & 74 & Head & 45 & Abdominal pain \\
\hline 3 & Ramuz et al. (2005) [5] & $\mathrm{F}$ & 31 & Body & 15 & Abdominal pain \\
\hline 4 & Périgny et al. (2008) [6] & $\mathrm{F}$ & 46 & Body & 17 & Diarrhea \\
\hline 5 & Hirabayashi et al. (2009) [7] & $\mathrm{F}$ & 47 & Head & 17 & Abdominal pain \\
\hline 6 & Baez et al. (2009) [8] & $\mathrm{F}$ & 60 & Body & 32 & $\begin{array}{l}\text { Bulge in right upper } \\
\text { quadrant }\end{array}$ \\
\hline 7 & Zemet et al. (2011) [9] & M & 49 & Head & 32 & $\begin{array}{l}\text { Fever, cough, and } \\
\text { malaise }\end{array}$ \\
\hline 8 & Nagata et al. (2011) [10] & M & 52 & Head & 40 & Abdominal pain \\
\hline 9 & Finzi et al. (2012) [11] & $\mathrm{F}$ & 62 & Head & 25 & No symptoms \\
\hline 10 & Al-Haddad et al. (2013) [12] & $\mathrm{F}$ & 38 & $\begin{array}{l}\text { Uncinate } \\
\text { process }\end{array}$ & 18 & Abdominal pain \\
\hline 11 & Okuwaki et al. (2013) [13] & $\mathrm{F}$ & 43 & Body & 100 & Abdominal pain \\
\hline 12 & Our patient & $\mathrm{F}$ & 17 & Head & 42 & Melena \\
\hline & 12 patients & $10 \mathrm{~F} / 2 \mathrm{M}$ & $\begin{array}{l}\text { Mean age } 48 \\
\text { (range 17-74) }\end{array}$ & $\begin{array}{l}\text { Body: } 5 \\
\text { Head: } 6 \\
\text { Uncinate } \\
\text { process: } 1\end{array}$ & $\begin{array}{c}\text { Mean } 36 \mathrm{~mm} \\
\text { (range } 15-100 \mathrm{~mm} \text { ) }\end{array}$ & $\begin{array}{c}\text { Abdominal pain: } 7 \\
\text { Bulge: } 1 \\
\text { Nonspecific } \\
\text { symptoms: } 2 \\
\text { GI } \\
\text { bleeding: } 1 \\
\text { No symptoms: } 1\end{array}$ \\
\hline
\end{tabular}

smooth muscle (actin and/or desmin) markers. The term "sugar tumors" refers to the clear cytoplasm of the perivascular epithelioid cells which is rich in glycogen $[15,20]$.

For the most part, PEComas are considered benign; however, a subset of PEComas behaves in a malignant fashion, leading to local invasion, multiple metastases, and death as observed with high-grade sarcomas. Recently, Folpe and Kwiatkowski have suggested criteria for malignancy, including a size greater than $5 \mathrm{~cm}$, mitotic count of more than 1 per 50 high-power fields, and necrosis [21]. Primary PEComas of the pancreas are extremely rare tumours with uncertain malignant potential. In the last fifteen years only twelve cases, including the one we report here, were published in the literature (Table 1). This patient group included ten women and two men (ratio $5: 1$ ) with a mean age of 48 years (age range from 17 to 74). Our patient is the youngest. Symptoms at diagnosis included abdominal pain in seven patients, diarrhea in one patient, a bulge in the right upper quadrant in one patient, and unspecific cold-like symptoms (fever, coughing, and fatigue) in one patient. One patient was asymptomatic, and PEComa was diagnosed using abdominal ultrasound. The tumors were located in the pancreatic head in five patients, in the pancreatic body in five patients, and in the uncinate process in one patient. The mean tumor diameter was $36 \mathrm{~mm}$ (range 15 to $100 \mathrm{~mm}$ ). Tumor rupture was found only in our patient.

Our patient had a relatively small tumor $(4,2 \mathrm{~cm} \times$ $4,9 \mathrm{~cm})$. Mitosis was rare and no necrosis was seen; thus Folpe's criteria for malignancy are negative for our patient. Most PEComas present with abdominal pain but our patient's first symptom was melena.
Radiographics findings with CT and MRI show that these lesions are significantly and heterogeneously enhanced on arterial phase, less enhanced on portal venous phase, and slightly hypodense on delayed phase [22]. Early recognition of pancreatic PEComas on imaging could dramatically impact both patient therapy and prognosis. Radiologists should be on high suspicion and consider the diagnosis of pancreatic PEComa if they encounter a well-defined, encapsulated, and hypovascular pancreatic mass [22].

Surgical resection represents the only curative approach for primary PEComa at presentation as well as for local recurrences and metastasis, as chemotherapy and radiotherapy have not demonstrated significant benefits [23]. Only recently limited clinical studies have reported encouraging results in terms of therapeutic response after oral administration of mTOR inhibitor in patients with metastatic PEComa [24]. Further study is warranted to determine the optimal management of these rare tumors.

\section{Conclusions}

Pancreatic PEComas are rare entities which most commonly present with abdominal pain. However, this case shows that these tumours can manifest with upper gastrointestinal bleeding.

\section{Conflict of Interests}

C. Petrides and coauthors have no conflict of interests. 


\section{References}

[1] G. Martignoni, M. Pea, D. Reghellin, G. Zamboni, and F. Bonetti, "PEComas: the past, the present and the future," Virchows Archiv, vol. 452, no. 2, pp. 119-132, 2008.

[2] G. Zamboni, M. Pea, G. Martignoni et al., "Clear Cell 'sugar' tumor of the pancreas: a novel member of the family of lesions characterized by the presence of perivascular epithelioid cells," American Journal of Surgical Pathology, vol. 20, no. 6, pp. 722730, 1996.

[3] A. L. Folpe, T. Mentzel, H.-A. Lehr, C. Fisher, B. L. Balzer, and S. W. Weiss, "Perivascular epithelioid cell neoplasms of soft tissue and gynecologic origin: a clinicopathologic study of 26 cases and review of the literature," The American Journal of Surgical Pathology, vol. 29, no. 12, pp. 1558-1575, 2005.

[4] G. Heywood, T. C. Smyrk, and J. H. Donohue, "Primary angiomyolipoma of the pancreas," Pancreas, vol. 28, no. 4, pp. 443-445, 2004.

[5] O. Ramuz, B. Lelong, M. Giovannini et al., "'Sugar' tumor of the pancreas: a rare entity that is diagnosable on preoperative fineneedle biopsies," Virchows Archiv, vol. 446, no. 5, pp. 555-559, 2005.

[6] M. Périgny, O. Larochelle, P. Hammel et al., "Pancreatic perivascular epithelioid cell tumor (PEComa)," Annales de Pathologie, vol. 28, no. 2, pp. 138-142, 2008.

[7] K. Hirabayashi, N. Nakamura, H. Kajiwara et al., "Perivascular epithelioid cell tumor (PEComa) of the pancreas: immunoelectron microscopy and review of the literature," Pathology International, vol. 59, no. 9, pp. 650-655, 2009.

[8] J. C. Baez, J. M. Landry, J. R. Saltzman, X. Qian, M. J. Zinner, and K. J. Mortelé, "Pancreatic PEComa (sugar tumor): MDCT and EUS features," Journal of the Pancreas, vol. 10, no. 6, pp. 679-682, 2009.

[9] R. Zemet, H. Mazeh, T. Neuman, H. R. Freund, and A. Eid, "Asymptomatic pancreatic perivascular epithelial cell tumor (PEComa) in a male patient: report and literature review," Journal of the Pancreas, vol. 12, no. 1, pp. 55-58, 2011.

[10] S. Nagata, M. Yuki, M. Tomoeda et al., "Perivascular epithelioid cell neoplasm (PEComa) originating from the pancreas and metastasizing to the liver," Pancreas, vol. 40, no. 7, pp. 1155-1157, 2011.

[11] G. Finzi, D. Micello, G. Wizemann, F. Sessa, and C. Capella, "Pancreatic PEComa: a case report with ultrastructural localization of HMB-45 within melanosomes," Ultrastructural Pathology, vol. 36, no. 2, pp. 124-129, 2012.

[12] M. Al-Haddad, H. M. Cramer, T. Muram, X. Wang, and H. A. Pitt, "Perivascular epithelioid cell tumor: an unusual pancreatic mass diagnosed by EUS-FNA," Gastrointestinal Endoscopy, vol. 78, no. 1, pp. 165-167, 2013.

[13] K. Okuwaki, M. Kida, H. Masutani et al., "A resected perivascular epithelioid cell tumor (PEComa) of the pancreas diagnosed using endoscopic ultrasound-guided fine-needle aspiration," Internal Medicine, vol. 52, no. 18, pp. 2061-2066, 2013.

[14] K. Apitz, "Die Geschwülste und Gewebsmissbildungen der Nierenrinde. II Midteilung. Die mesenchymalen Neubildungen," Virchows Archiv, vol. 311, pp. 306-327, 1943.

[15] K. Yamashita and C. D. M. Fletcher, "PEComa presenting in bone: clinicopathologic analysis of 6 cases and literature review," American Journal of Surgical Pathology, vol. 34, no. 11, pp. 16221629, 2010.
[16] F. Khaja, A. Carilli, S. Baidas, A. Sriharan, and S. Norford, "PEComa: a perivascular epithelioid cell tumor in the livera case report and review of the literature," Case Reports in Medicine, vol. 2013, Article ID 904126, 4 pages, 2013.

[17] H. Niu, F. W. Wang, P. J. Zhang, and Z. Bing, "Cardiac epithelioid PEComa: report of two cases and review of the literature," Case Reports in Medicine, vol. 2012, Article ID 521678, 6 pages, 2012.

[18] M. Fassan, M. Cassaro, M. Vecchiato et al., "Malignant perivascular epithelioid cell tumor of the esophagus," Case Reports in Pathology, vol. 2012, Article ID 438505, 5 pages, 2012.

[19] S. Unluoglu, U. Bayol, N. Korkmaz, B. Ozenen, F. Ipekci, and E. E. Pala, "Perivascular epithelioid cell tumor of the ileum presenting as diverticulitis," Case Reports in Pathology, vol. 2012, Article ID 476941, 4 pages, 2012.

[20] J. L. Hornick and C. D. M. Fletcher, "PEComa: what do we know so far?” Histopathology, vol. 48, no. 1, pp. 75-82, 2006.

[21] A. L. Folpe and D. J. Kwiatkowski, "Perivascular epithelioid cell neoplasms: pathology and pathogenesis," Human Pathology, vol. 41, no. 1, pp. 1-15, 2010.

[22] Y. Tan and E.-H. Xiao, "Hepatic perivascular epithelioid cell tumor (PEComa): dynamic CT, MRI, ultrasonography, and pathologic features-Analysis of 7 cases and review of the literature," Abdominal Imaging, vol. 37, no. 5, pp. 781-787, 2012.

[23] H. B. Armah and A. V. Parwani, "Perivascular epithelioid cell tumor," Archives of Pathology and Laboratory Medicine, vol. 133, no. 4, pp. 648-654, 2009.

[24] A. J. Wagner, I. Malinowska-Kolodziej, J. A. Morgan et al., "Clinical activity of mTOR inhibition with sirolimus in malignant perivascular epithelioid cell tumors: targeting the pathogenic activation of mTORC1 in tumors," Journal of Clinical Oncology, vol. 28, no. 5, pp. 835-840, 2010. 


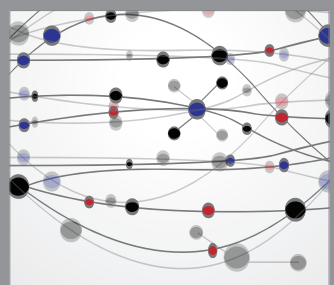

The Scientific World Journal
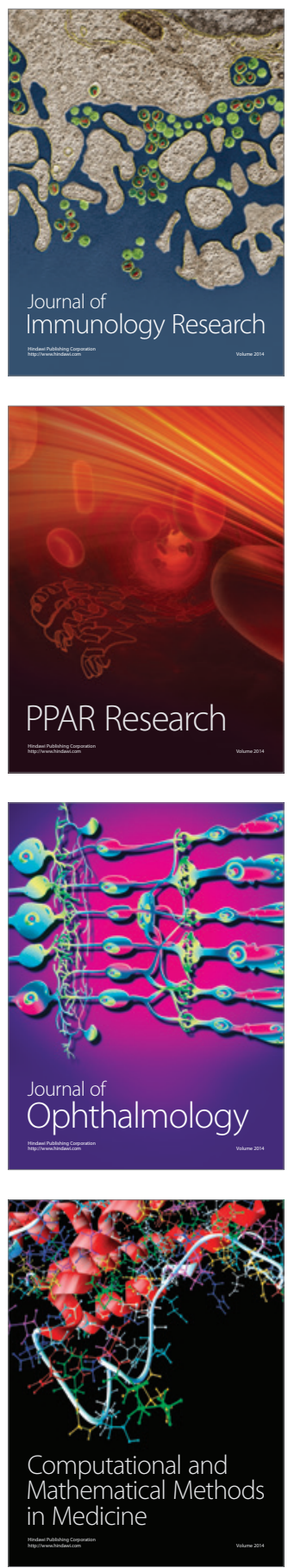

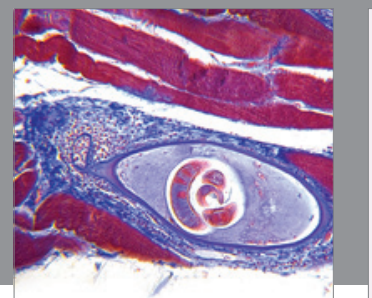

Gastroenterology

Research and Practice
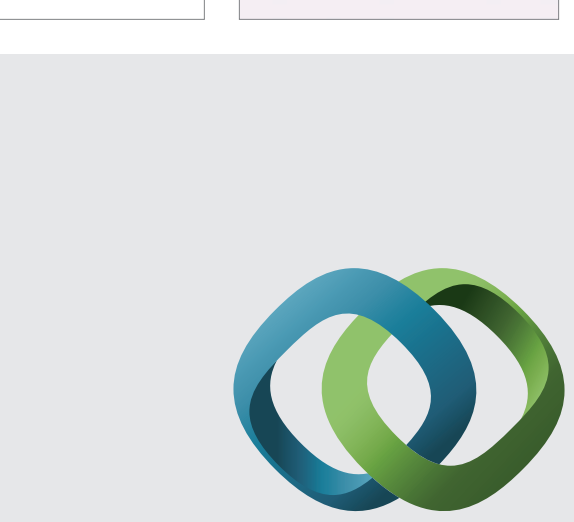

\section{Hindawi}

Submit your manuscripts at

http://www.hindawi.com
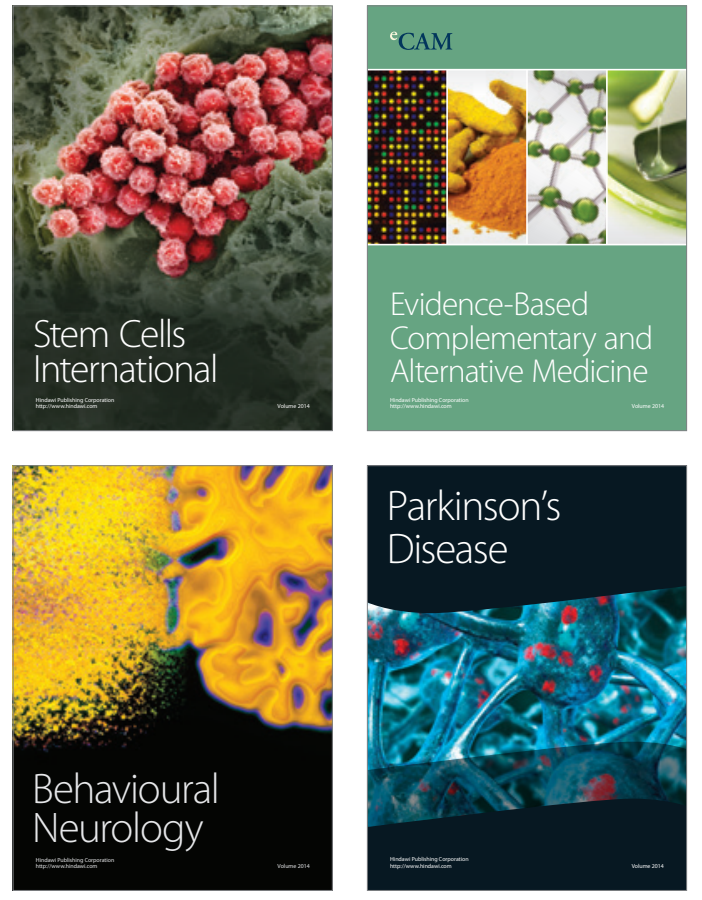
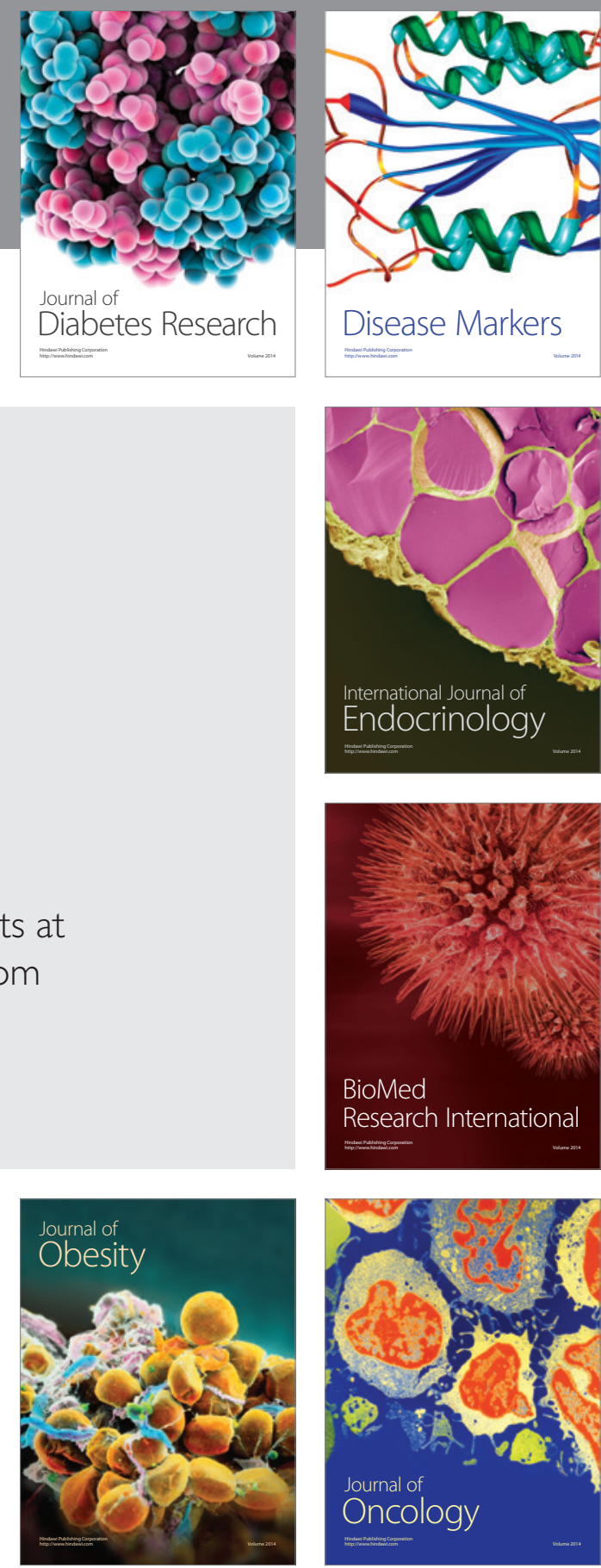

Disease Markers
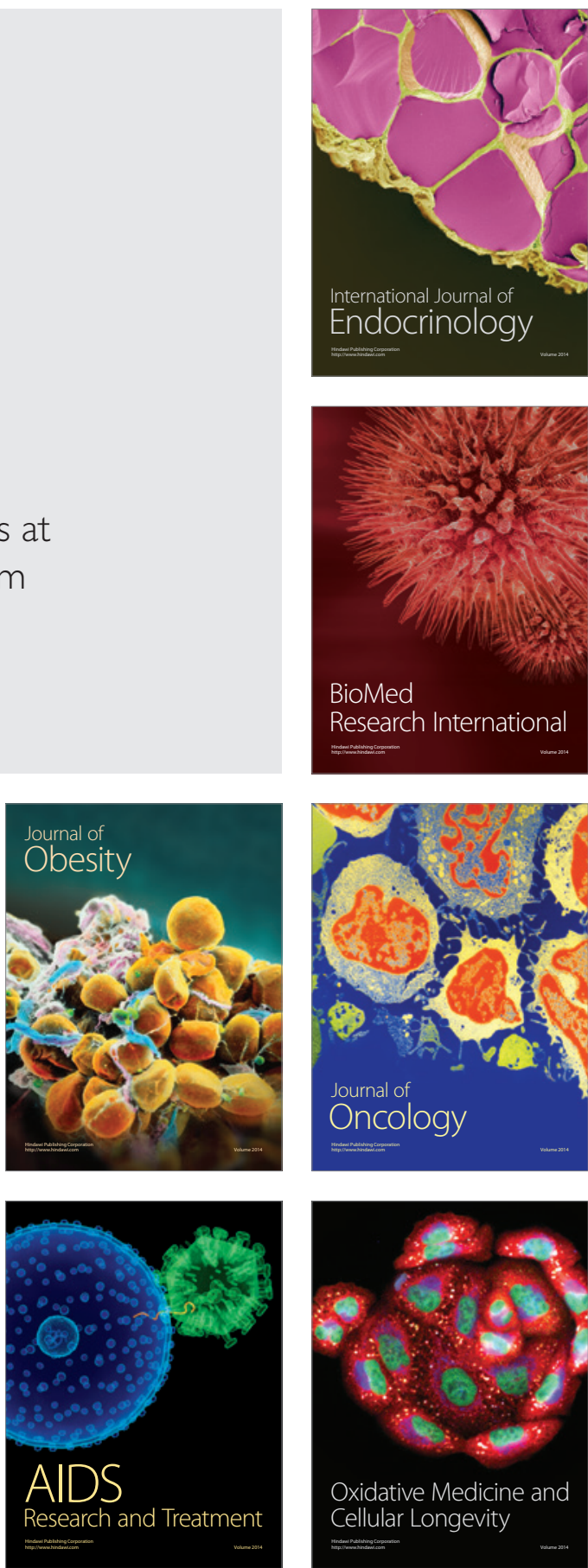